\title{
A Complete System to Generate Clean Water from a Contaminated Water Body by a Handmade Flower-Like Light Absorber
}

Muhammad Javed a, Sippi Pirah a, Yonghe Xiao a, Yilan Sun a, Yating Ji a, Muhammad Zubair Nawaz b Zaisheng Cai a, Bi Xu a*

a National Engineering Research Center for Dyeing and Finishing of Textiles, College of Chemistry, Chemical Engineering and Biotechnology, Donghua University, 2999 North Renmin Road, Shanghai, 201620 China.

${ }^{b}$ College of Science and Shanghai Institute of Intelligent Electronics and Systems, Donghua University, 2999 North Renmin Road, Shanghai, 201620 China.

E-mail address: xubi@dhu.edu.cn
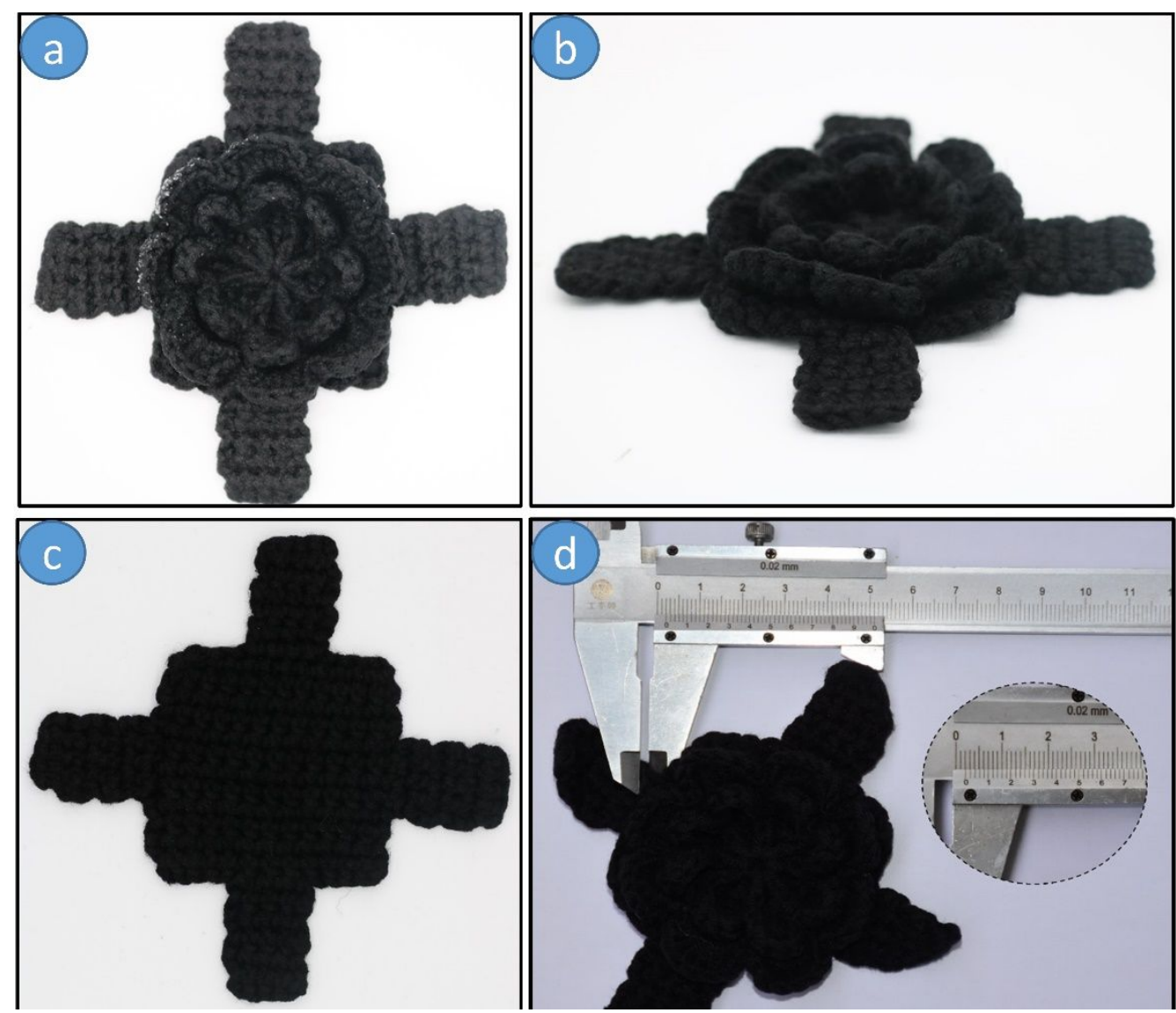

Figure S1. a) Handmade flower-like light absorber (HFLA) top view, b) HFLA side view. c) plain structure light absorber top view. d) Thickness of absorber layer. 


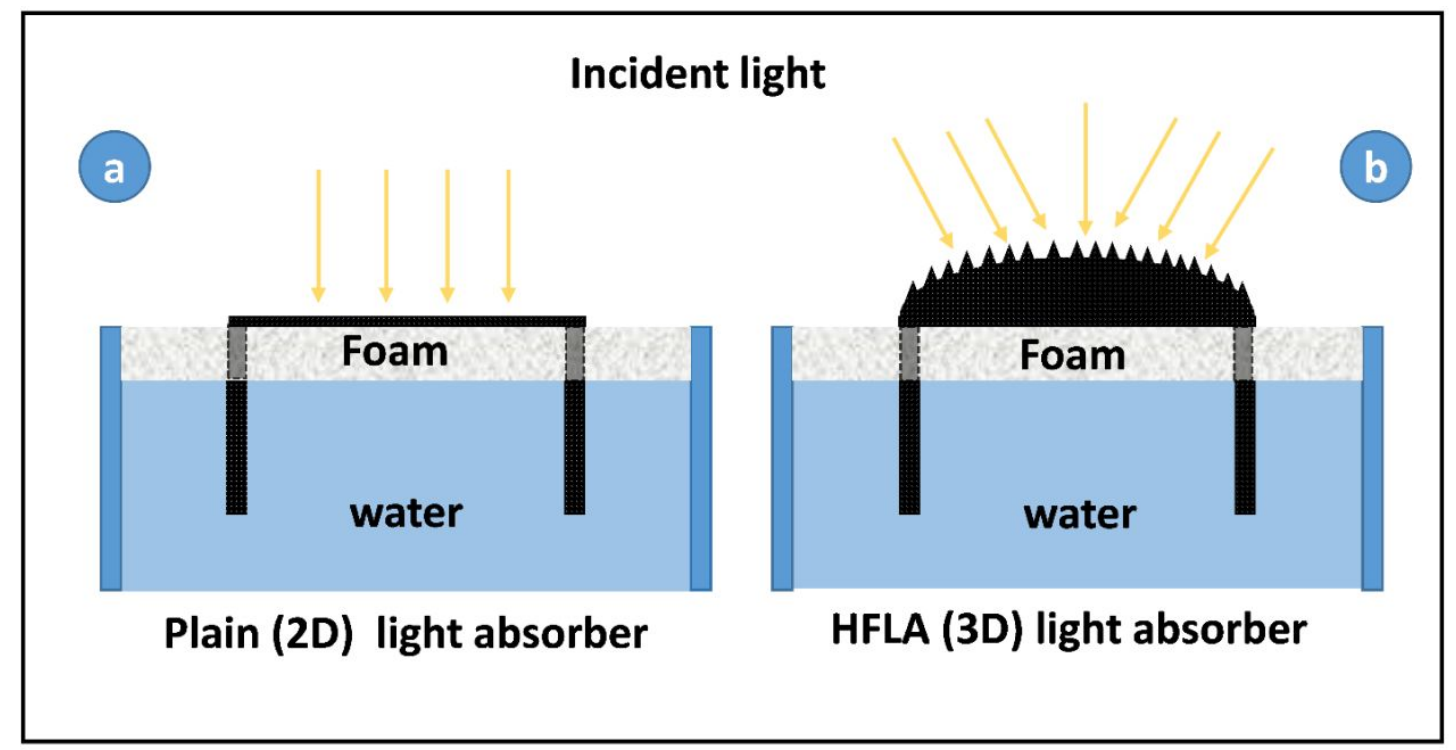

Figure S2. a) Plain structure (2D) light absorption, b) HFLA (3D) structure light absorption.

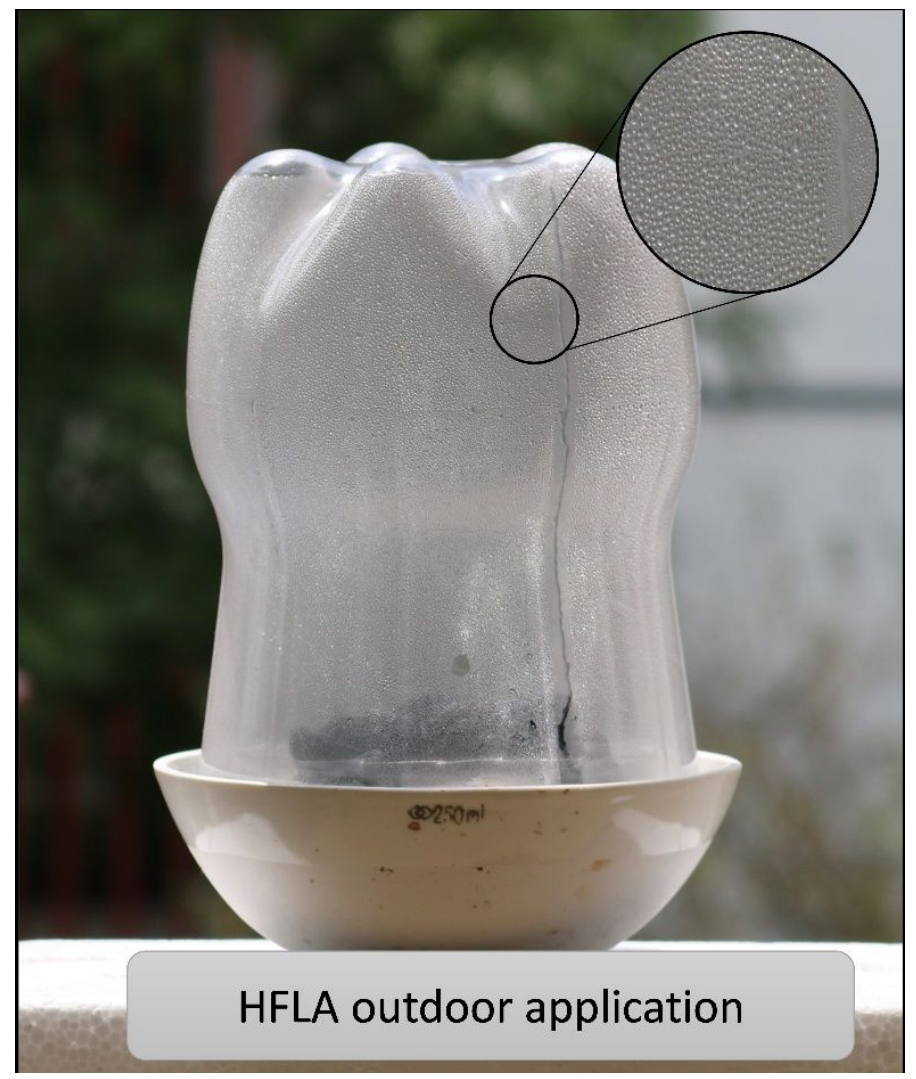

Figure S3. HFLA outdoor application in natural environment under sunlight. 